\title{
Recombinant Human Granulocyte-Macrophage Colony-Stimulating Factor Primes Neonatal Granulocytes for Enhanced Oxidative Metabolism and Chemotaxis ${ }^{1}$
}

\author{
MITCHELL S. CAIRO, CARMELLA VAN DE VEN, CYNTHIA TOY, DEBBIE MAUSS, AND \\ LEONARD SENDER \\ Division of Hematology/Oncology, Department of Pediatrics, Childrens Hospital of Orange County, \\ University of California, Irvine, California 92668
}

\begin{abstract}
Recombinant human granulocyte-macrophage colony-stimulating factor (rhGM-CSF) induces proliferation and differentiation of hematopoietic stem cells. Additionally, rhGM-CSF enhances the physiologic responses of adult polymorphonuclear leukocytes (PMN) especially with respect to oxidative metabolism and chemotaxis. Neonatal PMN are deficient in chemotaxis and have been demonstrated to have reduced oxidative responses in times of stress. We evaluated the priming effects of rhGMCSF (1-100 pmol/L) on cord (neonatal) superoxide production and chemotaxis. Cord and adult PMN were incubated with $100 \mathrm{pmol} / \mathrm{L}$ rhGM-CSF (Amgen, $4 \times 10^{7} \mathrm{U} /$ $\mathrm{mg}$ ) for 0-120 min and stimulated with N-formyl-l-methionyl-l-leucyl-phenylalanine. $\mathrm{RhGM-CSF}$ enhanced $\mathrm{O}_{2}^{-}$ production at all time periods with maximal priming at 60 $\min (147.97 \pm 11.14 \% p \leq 0.006)$ with less, but significant enhancement at $120 \mathrm{~min}(116.53 \pm 7.92 \% p \leq 0.05)$. Maximal adult $\mathrm{PMN} \mathrm{O}_{2}^{-}$release occurred at $120 \mathrm{~min}$ $(190.02 \pm 8.71 \% p \leq 0.003)$ and was more pronounced than cord PMN. RhGM-CSF $(100 \mathrm{pmol} / \mathrm{L} \times 30 \mathrm{~min})$ incubation of cord PMN also primed for increased PMN $\mathrm{O}_{2}^{-}$release after zymosan-activated serum stimulation ( $p$ $\leq 0.05)$ but not PMA $(p=N S)$. Co-incubating cord PMNs with $100 \mathrm{pmol} / \mathrm{L}$ rhGM-CSF and a murine anti-human GM-CSF antibody $(0-100 \mathrm{mcg} / \mathrm{ml})$ resulted in $95 \%$ inhibition of the priming effect of rhGM-CSF enhancement of cord $\mathrm{PMN} \mathrm{O}_{2}^{-}$release. RhGM-CSF, primed cord PMN for enhanced chemotaxis during early incubation ( $5 \mathrm{~min}$ ) with both $\mathrm{N}$-formyl-l-methionyl-l-leucyl-phenylalanine $\left(10^{-8} \mathrm{M}\right)$ and Escherichia coli filtrate $(113.54 \pm 6.11 \% p$ $\leq 0.025$ and $110.84 \pm 4.69 \% p \leq 0.001$ ), respectively, but not at 30-min or 60-min incubation. These studies suggest that rhGM-CSF similarly primes neonatal PMN like adult PMN for enhanced in vitro PMN oxidative responses and chemotaxis. (Pediatr Res 26: 395-399, 1989)
\end{abstract}

\section{Abbreviations}

PMN, polymorphonuclear leukocyte (bands + neutrophils) rhGM-CSF, recombinant human granulocyte-macrophage colony stimulating factor

Received January 13, 1989; accepted June 7, 1989.

Correspondence Mitchell S. Cairo, M.D., Associate Director, Hematology/ Oncology, Research Director, Hematology/Oncology Research and Bone Marrow Transplantation, Childrens Hospital of Orange County, 455 S. Main, Orange, CA 92668.

Supported in part by Pediatric Cancer Research Foundation Grant 1987-A

${ }_{1}^{1}$ Presented in part at the Western Society of Pediatric Research, Carmel, CA February 1989 and Society of Pediatric Research, Washington, D.C., May 1989.
$\mathrm{O}_{2}^{-}$, superoxide

FMLP, N-formyl-l-methionyl-l-leucyl-phenylalanine

PMA, phorbol myristate acetate

CFU-GM, Colony forming unit-granulocyte-macrophage

SOD, superoxide dismutase

ZAS, zymosan activated serum

Ab, antibody

DMSO, dimethylsulfoxide

G-BSA, Gey's media with $2 \%$ BSA

GM-CSF is a small glycoprotein $(22000 \mathrm{D})$ which has been purified to homogeneity from a medium conditioned by the Mo T lymphoblastoid cell line (1). Recently, it has been determined that cell division and differentiation of hematopoietic progenitor stem cells are dependent on the continuous or intermittent supply of specific glycoproteins such as rhGM-CSF (2-4). Both the natural and the recombinant forms of GM-CSF stimulate granulocyte, macrophage, and eosinophil bone marrow colonies in vitro. (5). Although growth factors are necessary for adequate proliferation and release of bone marrow progenitor cells, they also have been demonstrated to enhance the function of mature effector cells.

Conjointly with its role of inducing proliferation and differentiation of hematopoietic stem cells, GM-CSF has been demonstrated to enhance adult host defense by improving the functional capabilities of adult mature neutrophils. Incubation of rhGM-CSF with adult PMN enhances the response of neutrophils with respect to oxidative metabolism, locomotion (chemotaxis), phagocytosis, and cytotoxicity $(6,7)$. Specifically, GMCSF augments FMLP, C5a, and leukotriene $\mathrm{B}_{4}$-induced superoxide anion production $(8,9)$, enhances FMLP stimulated chemotaxis (9), and promotes phagocytosis of opsonized Staphylococcus aureus (10). GM-CSF has also recently been demonstrated to induce the expression of surface active adhesion glycoproteins such as $\mathrm{C} 3 \mathrm{bi}$ resulting in the acceleration of adult PMN aggregation (11). Unfortunately, all of the above enhanced PMN activity primed by rhGM-CSF, have been demonstrated with adult PMN and little is known about the potential effect of rhGM-CSF with neonatal PMNs.

Neonatal host defense in the animal and human neonate is immunologically immature and contributes significantly to the high incidence of overwhelming sepsis in the preterm and term newborn (12). Humoral and phagocytic immunity are both deficient in neonatal host defense. A recent review by Hill (13) summarized the variety of biochemical, structural, and functional abnormalities that have been described in neonatal PMN. 
Inasmuch as rhGM-CSF has been demonstrated to prime adult PMN for increased functional activity, we examined the effects of rhGM-CSF on the modulation of PMN physiologic activity in the newborn. This study investigated the biologic effects of rhGM-CSF on cord (neonatal) PMN oxidative metabolism, chemotaxis, and bacterial killing.

\section{MATERIALS AND METHODS}

$R h G M-C S F$. rhGM-CSF supplied by Amgen Biologicals, Thousand Oaks, CA, is expressed in Escherichia coli and purified to apparent homogeneity before formulation in $0.025 \%$ human serum albumin and PBS. Purity of rhGM-CSF was confirmed to be more than $95 \%$ by the presence of a single protein band by SDS-PAGE. Biologic activity of $4 \times 10^{7} \mathrm{U} / \mathrm{mg}$ was determined by CFU-GM of nonadherent human bone marrow cells or by KG-1 colony formation in semisolid media with activity at $10^{-11}$ to $10^{-12} \mathrm{M}$. GM-CSF was shown to be free of measurable endotoxin by the Limulus amebocyte lysate assay. GM-CSF was used at concentrations in the range of $1-100 \mathrm{pm} / \mathrm{L}$ reflecting the reported enhancement of adult neutrophil oxidative metabolism in response to FMLP to study its effect on cord and adult neutrophil activity (14).

Materials. PMA, FMLP, and zymosan particles were purchased from Sigma Chemical Co. (St. Louis, MO). PMA was dissolved in DMSO, $1 \mathrm{mg} / \mathrm{mL}$, aliquoted, and stored at $-20^{\circ} \mathrm{C}$ until used at a final concentration of $2 \mu \mathrm{M}$. FMLP was dissolved in DMSO at $10^{-2} \mathrm{M}$, aliquoted and stored at $-20^{\circ} \mathrm{C}$, and finally used at final concentrations of $10^{-6}$ to $10^{-9} \mathrm{M}$. ZAS was prepared by boiling zymosan particles suspended in normal saline for $1 \mathrm{~h}$. The particles were cooled, centrifuged and resuspended in normal saline for storage at $-20^{\circ} \mathrm{C}$. Autologous serum was later added to the zymosan particles, and incubated for $30 \mathrm{~min}$ at $37^{\circ} \mathrm{C}$. The particles were then centrifuged and the serum removed for assay, at a final concentration of $10 \%$. E. coli filtrate was prepared by culturing the microorganism to maximum phase growth $(24 \mathrm{~h})$ in brain heart infusion (Difco, Detroit, MI), centrifuging the culture, and collecting the supernatant broth which was then filtered sterilely, aliquoted, and stored at $-20^{\circ} \mathrm{C}$ (final concentration $10 \%$ solution).

Anti-GM-CSF MAb. Anti-GM-CSF MAb (Genzyme, Boston, $\mathrm{MA}$ ) is a murine MAb generated against purified rhGM-CSF, and is of the IgG1 subclass. It was received as $95 \%$ pure as determined by SDS gel electrophoresis, and is neutralizing for GM-CSF activity (hematopoiesis). Complete neutralization of $50 \mathrm{U}$ of GM-CSF could be obtained with $1 \mu \mathrm{g}$ of antibody, and no detectable cross-reaction with human G-CSF, IL-3, or mouse GM-CSF can be measured. The antibody was diluted to concentrations of 0.32 to $100 \mu \mathrm{g} / \mathrm{mL}$ to study its inhibitory effect on the priming of GM-CSF in neutrophil superoxide production.

Isolation of human PMN. Heparinized venous blood was drawn from normal volunteers in accordance with the principles of the Declaration of Helsinki. Venous cord blood was drawn from the umbilical vessels of placentas of normal, full-term, nonstressed infants immediately after vaginal delivery or cesarean section. Both cord and adult donor red blood cells were allowed to sediment, after the addition of $6 \%$ Dextran- 70 in $0.9 \%$ saline (McGaw Laboratories, Irvine, CA). The leukocyteenriched plasma was collected, layered on a Ficoll-Hypaque gradient $(p=1.077)$, and centrifuged for $15 \mathrm{~min}$. PMN were recovered in the cell pellet, and any remaining erythrocytes were hemolyzed by hypotonic lysis. Isolated PMN were then suspended in Dulbecco's pH 7.4, or PBS, pH 7.4 with 5 mM glucose at various concentrations depending on particular assay requirements. PMN isolated by density gradient separation were purified to greater than $98 \%$ homogeniety. Cell viability as measured by trypan blue exclusion was more than $99 \%$. PMN were used in the following assays within $2 \mathrm{~h}$ of collection.

Superoxide production. Superoxide release was assessed as the SOD sensitive reduction of ferricytochrome $C$ as previously described $(15,16)$. Aliquots of PMN were exposed to various concentrations of GM-CSF for 5-120 min at $37^{\circ} \mathrm{C}$. Cytochrome $\mathrm{C}(1.19 \mathrm{mM})$ and cytochalasin $\mathrm{B}(5 \mu \mathrm{g} / \mathrm{mL})$ were added, and the cells were stimulated by either PMA, FMLP, or ZAS at concentrations given above, at $37^{\circ} \mathrm{C}$ for $5 \mathrm{~min}$. To arrive at a nonreactive control value, one sample of each treatment received $100 \mu \mathrm{g}$ of SOD. The reaction was stopped with the addition of N-ethylmalemide (1 mM) (Sigma), and absorption at $550 \mathrm{~nm}$ of the sample supernates was measured on a Gilford spectrophotometer (Oberlin, $\mathrm{OH}$ ). Results are expressed as nmol reduced cytochrome $\mathrm{C}$ using the extinction coefficient of $21.1 \times 10^{3} \mathrm{M}^{-1}$ $\mathrm{cm}^{-1}$. Control values of PMN incubated with PBS and $0.025 \%$ human albumin and cytochalasian B were obtained at each time point studied in all assays of superoxide production.

To determine if the observed effects of rhGM-CSF were primarily due to the CSF rather than extraneous stimulation from contamination by other stimulants, graded concentrations of anti-GM-CSF antibody and PBS control were preincubated vol/ vol with and without GM-CSF for $1 \mathrm{~h}$ at room temperature Cord neutrophils were then exposed to the antibody/GM-CSF mixtures for $30 \mathrm{~min}$ at $37^{\circ} \mathrm{C}$, and superoxide release was measured as described above.

Granulocyte chemotaxis. The Gallin modification of the Boyden chamber technique was performed to assay for chemotaxis activity (17). The Boyden apparatus was prepared by inserting two filters $(0.4$ and $5.0 \mu \mathrm{m}$, Nucleopore, Pleasanton, CA) to separate the upper and lower chambers. Adult or cord PMN were labeled with sodium 51-chromate (ICN Radiochemicals, Irvine, CA), and suspended in G-(GIBCO, Grand Island, NY) BSA (Difco, Detroit, MI). Appropriate amounts of GM-CSF or $0.025 \%$ albumin in normal saline were then added, and the cells were incubated for 5 to $120 \mathrm{~min}$ at $37^{\circ} \mathrm{C}$. The lower chamber of the Boyden apparatus was then filled with a chemoattractant solution containing G-BSA, $1.0 \%$ donor or cord serum, and either $10 \% \mathrm{E}$. coli filtrate or FMLP $\left(10^{-6}\right.$ to $\left.10^{-9} \mathrm{M}\right)$. The treated cells were added to the upper chamber. After incubation at $37^{\circ} \mathrm{C}$ for $90 \mathrm{~min}$, the filters were separated and the $0.4-\mu \mathrm{m}$ filters containing the trapped migrating cells were counted in a Beckman LS1800 scintillation counter (Beckman Instruments Inc., Fullerton, CA). Aliquots of $100 \%$ chromium labeled PMN were analyzed in the same manner, and results are expressed as percent chemotaxis, i.e. migrated cell $\mathrm{cpm} / 100 \%$ labeled cell $\mathrm{cpm}$.

Bactericidal activity. Bacterial killing capability was measured by a modification of the Quie method, as described previously (18). Briefly, Staphylococcus aureus (American Type Culture no. 27217, Rockville, MD) was subcultured to obtain maximum phase growth, diluted in Kreb's ringers phosphate buffer with $0.1 \%$ glucose and $1.0 \%$ BSA at a concentration of approximately $2 \times 10^{8}$ bacteria/mL, OD 590 . Bacteria were opsonized with control or cord serum for $10 \mathrm{~min}$ before the assay. Aliquots of PMN were isolated from donor or cord blood before the Ficoll separation, and incubated with various doses of GM-CSF for 5$120 \mathrm{~min}$ at $37^{\circ} \mathrm{C}$. The treated and untreated cells were then mixed with the opsonized bacteria at a ratio of $1: 4$ and incubated for $15 \mathrm{~min}$ at $37^{\circ} \mathrm{C}$. Aliquot samples of bacteria and cell suspension were serially diluted in sterile water, and finally plated in warm nutrient agar (Difco, Detroit, MI). Colony growth was measured after overnight incubation, and results are expressed as percent bacteria killed.

Statistical analysis. All results are expressed as mean values \pm SEM for three or more experiments. The probability of significant differences when examining treatment groups was determined with the use of the unpaired Student's $t$ test; whereas the probability of significant differences when examining multiple treatments was determined by using the analysis of variance followed by the Student-Newman-Keuls multiple range test to define the unique subsets within the study. Statistical analysis was performed using the Biostat-I statistical program (Sigma Soft, Placentia, CA) for the IBM personal computer. $p$ values $\leq 0.05$ were considered significant. 


\section{RESULTS}

Effect of rh-GM-CSF on superoxide production in neonatal $P M N$. To determine the effect of incubating cord PMN with various concentrations of GM-CSF, a dose response of rhGMCSF $(5,10,50,100 \mathrm{pmol} / \mathrm{L})$, incubated with neonatal PMN followed by stimulation with FMLP $\left(10^{-7} \mathrm{M}\right)$ was undertaken. A significant effect occurred at $10 \mathrm{pmol} / \mathrm{L}$ [152.54\% control $(10$ $\mathrm{pmol} / \mathrm{L})]$ and this enhanced effect continued up to $100 \mathrm{pmol} / \mathrm{L}$ $[130.34 \pm 7.40 \%$ control $(100 \mathrm{pmol} / \mathrm{L})] ; p \leq 0.001$ and $\leq 0.001$, respectively. We next used $100 \mathrm{pmol} / \mathrm{L}$ of rhGM-CSF incubated with cord PMN and then stimulated with FMLP $\left(10^{-7} \mathrm{M}\right)$ to study the time response of GM-CSF incubation. These studies demonstrated maximal priming to occur between 30 and 60 min $(p \leq 0.006)$ with less, but still significant enhancement at 120 min $(p \leq 0.05)$ (Fig. 1). After selecting a maximal time of incubation $(30 \mathrm{~min})$, we studied the dose response of FMLP $\left(10^{-9}-10^{-6} \mathrm{M}\right)$ of cord PMN incubated with $100 \mathrm{pmol} / \mathrm{L} \mathrm{rhGM}-$ CSF. These experiments demonstrated significant enhancement at both $10^{-7}$ and $10^{-6} \mathrm{M},(p \leq 0.005)$ and $(p \leq 0.001)$, respectively.

Next, we varied the agonist to determine if $100 \mathrm{pmol} / \mathrm{L} \mathrm{rhGM-}$ CSF incubation for $30 \mathrm{~min}$ with neonatal PMN resulted in significant enhancement with other stimulants. ZAS but not PMA stimulation resulted in significant enhancement of rhGMCSF treated neonatal PMN superoxide generation (Table 1). In an attempt to abrogate the effects of priming neonatal PMN with rhGM-CSF, and to eliminate any other contaminating cause for PMN functional activation, we coincubated neonatal PMN with $100 \mathrm{pmol} / \mathrm{L}$ rhGM-CSF and studied the dose response of adding additional anti-rhGM-CSF $\mathrm{Ab}(2,32,64,100 \mu \mathrm{g} / \mathrm{mL})$ followed by FMLP stimulation $\left(10^{-7} \mathrm{M}\right)$. Anti-rhGM-CSF antibody itself had no effect on neonatal PMN superoxide generation (149.2 \pm 11 versus $138.9 \pm 14 \mathrm{nmol} / 10^{7}$ cells $)(100 \mu \mathrm{g} / \mathrm{mL} \mathrm{Ab}$ versus control) $p=$ NS. However, anti-GM-CSF antibody coincubated with rhGM-CSF resulted in significant inhibition of enhanced superoxide anion production at 32,64 , and $100 \mu \mathrm{g} / \mathrm{mL} \mathrm{Ab}$ resulting in $\leq 95 \%$ inhibition at $100 \mu \mathrm{g} / \mathrm{mL}$ (Fig. 2; Table 1).

Incubating rhGM-CSF $100 \mathrm{pmol} / \mathrm{L}$ for $0-120 \mathrm{~min}$ with adult PMN demonstrated significant enhancement of adult PMN superoxide generation at 30,60 , and $120 \mathrm{~min}$. In contrast, however, similar doses of rhGM-CSF resulted in an earlier but less maximal response with neonatal PMN (30-60 min) compared to the priming effect of rhGM-CSF with adult PMN (Fig. 1).

Effect of rhGM-CSF on chemotaxis in neonatal PMN. The

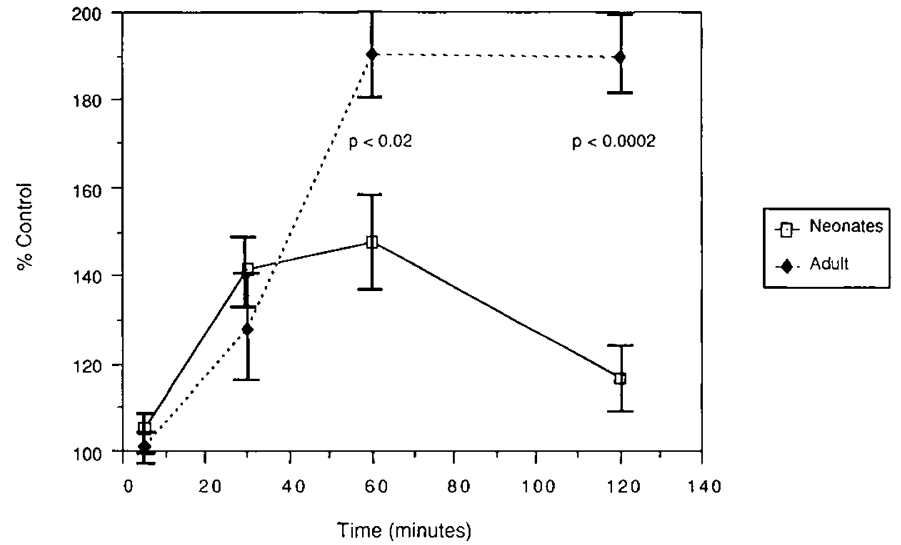

Fig. 1. Comparison of adult versus cord neutrophil superoxide production after exposure to rhGM-CSF. Adult and cord neutrophils $(1 \times$ $10^{7} / \mathrm{mL}$ ) were incubated for $30 \mathrm{~min}$ with $100 \mathrm{pmol} / \mathrm{L}$ rhGM-CSF $37^{\circ} \mathrm{C}$. After the addition of cytochrome C $(1.19 \mathrm{mM})$ and cytochalasin $B(5$ $\mu \mathrm{g} / \mathrm{mL})$, the cells were stimulated with FMLP $\left(10^{-7} \mathrm{M}\right)$ for $5 \mathrm{~min}$. Results are expressed as mean percent of control \pm SEM of five experiments done in triplicate. Cord control $138.86 \pm 13.9 \mathrm{nmol} / 10^{7}$ cells at $30 \mathrm{~min}$. Adult control $124.72 \pm 14.4 \mathrm{nmol} / 10^{7}$ cells at $120 \mathrm{~mm}$.
Table 1. Neutrophil superoxide production (mean $\pm S E M$ ) with different agonists after stimulation with and without GM-CSF and antibody ( $p<0.05$ is considered significant $)^{*}$

\begin{tabular}{|c|c|c|c|}
\hline & & $\begin{array}{c}\mathrm{O}_{2}^{-} \\
\text {Production } \\
\left(\mathrm{nmol} / 10^{7} \mathrm{c}\right)\end{array}$ & $p$ value \\
\hline FMLP & $\begin{array}{l}\text { Control } \\
\text { GM-CSF }\end{array}$ & $\begin{array}{l}199.6 \pm 17.7 \\
285.3 \pm 35.8\end{array}$ & $0.001 \uparrow(n=5)$ \\
\hline ZAS & $\begin{array}{l}\text { Control } \\
\text { GM-CSF }\end{array}$ & $\begin{array}{l}174.94 \pm 14.1 \\
182.39 \pm 14.3\end{array}$ & $<0.05 \dagger(n=5)$ \\
\hline PMA & $\begin{array}{l}\text { Control } \\
\text { GM-CSF }\end{array}$ & $\begin{array}{l}307.20 \pm 24.0 \\
335.28 \pm 14.8\end{array}$ & $\mathrm{NS}(n=3)$ \\
\hline FMLP & $\begin{array}{l}\text { Control + Ab } \\
\mathrm{GM}-\mathrm{CSF}+\mathrm{Ab}\end{array}$ & $\begin{array}{l}149.16 \pm 11.2 \\
144.93 \pm 12.0\end{array}$ & $\mathrm{NS}(n=6)$ \\
\hline
\end{tabular}

* Superoxide production of cord PMN after incubation with $100 \mathrm{pM} /$ L rhGM-CSF or anti-GM-CSF/GM-CSF and stimulation with various agonists. $1 \times 10^{7} / \mathrm{mL}$ PMN were incubated for $30 \mathrm{~min}$ with rhGM-CSF at $37^{\circ} \mathrm{C}$. Cytochrome $\mathrm{C}(1.19 \mathrm{mM})$ and cytochalasim $\mathrm{B}(5 \mu \mathrm{g} / \mathrm{mL})$ were added, and the cells stimulated with FMLP $\left(10^{-7} \mathrm{M}\right)$ for 5 min or, ZAS (10\% solution) or PMA $(2 \mu \mathrm{M})$ for $10 \mathrm{~min}$. To abrogate the effect of rhGM-CSF, $100 \mu \mathrm{g} / \mathrm{mL}$ of anti-GM-CSF antibody was incubated with the growth factor for $1 \mathrm{~h}$ at room temperature and the antibody rhGMCSF mixture was added to cord PMN for another 30-min incubation. The cells were then stimulated with FMLP $\left(10^{-7} \mathrm{M}\right)$ for $5 \mathrm{~min}$ as described above. Results are expressed as nmol reduced cytochrome $\mathrm{C}$ / $10^{7}$ cells, and are presented as mean values \pm SEM of four to six experiments done in triplicate.

$\dagger p$ values were calculated from data expressing superoxide produced as percentage of control.

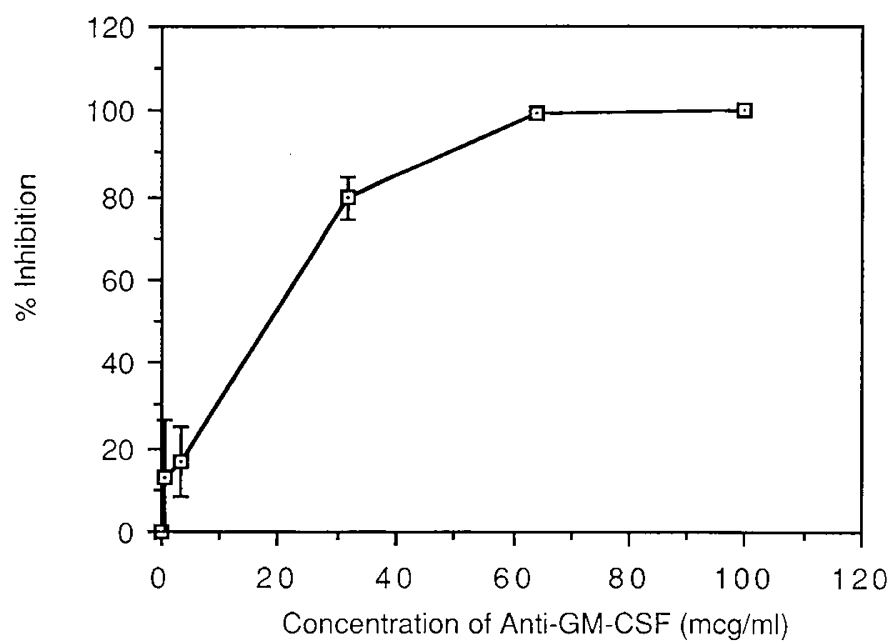

Fig. 2. Effect of graded concentrations of anti-rhGM-CSF antibody on the modulation of GM-CSF action on superoxide production of cord neutrophils. Concentrations of anti-GM-CSF antibody $0-100 \mu \mathrm{g} / \mathrm{mL}$ were preincubated with the growth factor $(\mathrm{vol} / \mathrm{vol})$ for $1 \mathrm{~h}$ at room temperature. Cord neutrophils were then exposed to the antibody/GM$\mathrm{CSF}$ mixture for $30 \mathrm{~min}$ at $37^{\circ} \mathrm{C}$. Superoxide release was measured as described in Figure 1. Results are expressed as mean percent of control \pm SEM of six experiments done in triplicate.

time course of rhGM-CSF enhancement of neonatal PMN chemotaxis is shown in Figure 3. Significant priming by rhGM$\mathrm{CSF}$ ( $100 \mathrm{pmol} / \mathrm{L}$ ) with neonatal PMN and FMLP as the chemoattractant occurred very early $(5 \mathrm{~min})(p \leq 0.025)$ with a return to normal activity after 30 - or 60 -min incubation (Fig. 3). A second agonist, $E$. coli filtrate, also resulted in significant rhGMCSF enhancement of neonatal PMN chemotaxis after 5-min incubation $(110.84 \pm 4.69 \%$ of control $)(p \leq 0.05)$ with a return 
to normal at $30-$ and $60-$ min incubation. This rapid enhancing effect of rhGM-CSF on neonatal PMN locomotion (chemotaxis) was in contrast to a later and more pronounced effect seen with rhGM-CSF and neonatal PMN superoxide release.

Effect of rhGM-CSF on bacterial killing of neonatal PMN. Neonatal PMN incubated with unopsonized Staphylococcus aureus were unable to efficiently kill bacteria with or without rhGM-CSF (data not shown). Neonatal PMN were then challenged with opsonized bacteria (autologous serum) following 100 $\mathrm{pmol} / \mathrm{L}$ rhGM-CSF incubation for 0-120 min. Enhancement of neonatal PMN bacterial killing was observed after 120 -min incubation but not at 30 or $60 \mathrm{~min}$ of incubation with rhGM-CSF; at $120 \mathrm{~min}, n=3120.9 \pm 5.4 \%$ of control $(p \leq 0.05)$ (control versus rhGM-CSF) (Fig. 4).

\section{DISCUSSION}

Numerous in vitro abnormalities have been demonstrated in neonatal PMN, especially in times of stress or infection. These deficits include decreased deformability and chemotaxis $(19,20)$, defective opsonic activity and phagocytosis (21), a discrepancy between superoxide and hydroxyl radical generation (22), reduced oxidative responses in stressed newborns (23) and impaired bacterial killing in newborns stressed or concurrently infected (24). These qualitative and additional quantitative abnormalities in neonatal myeloid bone marrow precursors and circulating PMN have suggested the need for additional adjuvant therapy in the treatment of overwhelming neonatal sepsis (25).

RhGM-CSF administered as a daily intravenous infusion, has recently been shown to enhance peripheral PMN oxidative metabolism in primates (26) and correct defects in phagocytosis and bacterial killing in patients with AIDS in vivo (27). We postulated that rhGM-CSF might also prime neonatal PMN for enhanced functional activity. RhGM-CSF $(1-100 \mathrm{pmol} / \mathrm{L})$, by itself, was not found to be a direct stimulant of neonatal PMN. When rhGM-CSF was incubated with cord PMN before being stimulated by a chemoattractant, rhGM-CSF primed neonatal PMN for enhanced superoxide production with FMLP, ZAS, but not PMA stimulation. The results in this neonatal study were similar to those effects seen in adult PMNs primed with rhGM-CSF (8). The difference between rhGM-CSF priming neonatal and adult PMN is the degree and time of maximal enhancement. However, any differences between our cord PMN studies and adult PMN studies should be taken with caution because cord PMN may be

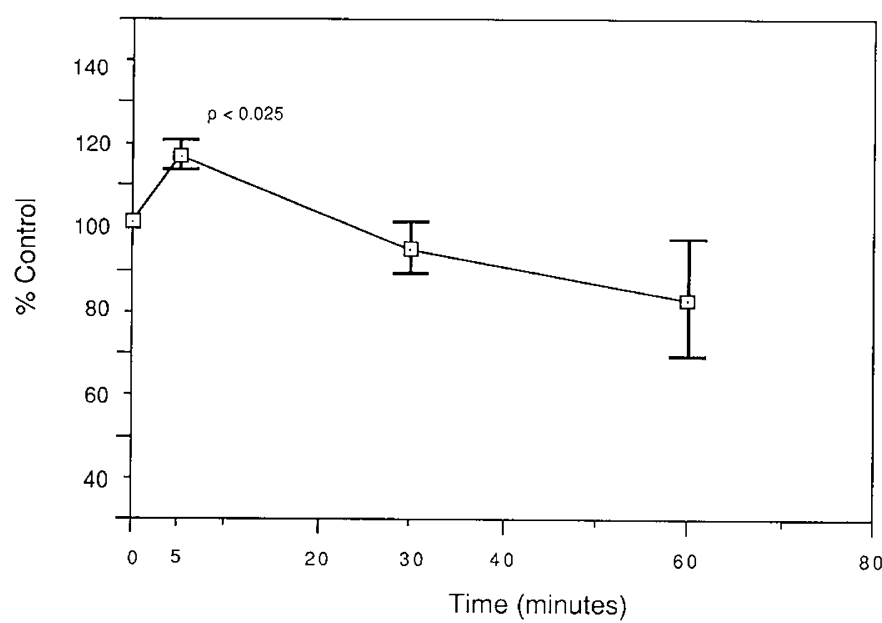

Fig. 3. Effect of rhGM-CSF on chemotaxis in neonatal neutrophils. The Gallin modification of the Boyden chamber technique was used. Cord PMN $\left(1 \times 10^{7} / \mathrm{mL}\right)$ were labeled with sodium 51-chromate and incubated for various time intervals $(0-60 \mathrm{~min})$ with $100 \mathrm{pmol} / \mathrm{L} \mathrm{rhGM-}$ CSF. Cells were placed in the Boyden chamber with FMLP $\left(10^{-8} \mathrm{M}\right)$ as the chemoattractant and incubated for $90 \mathrm{~min}$. Results are expressed as mean percent of control \pm SEM of five experiments done in triplicate.

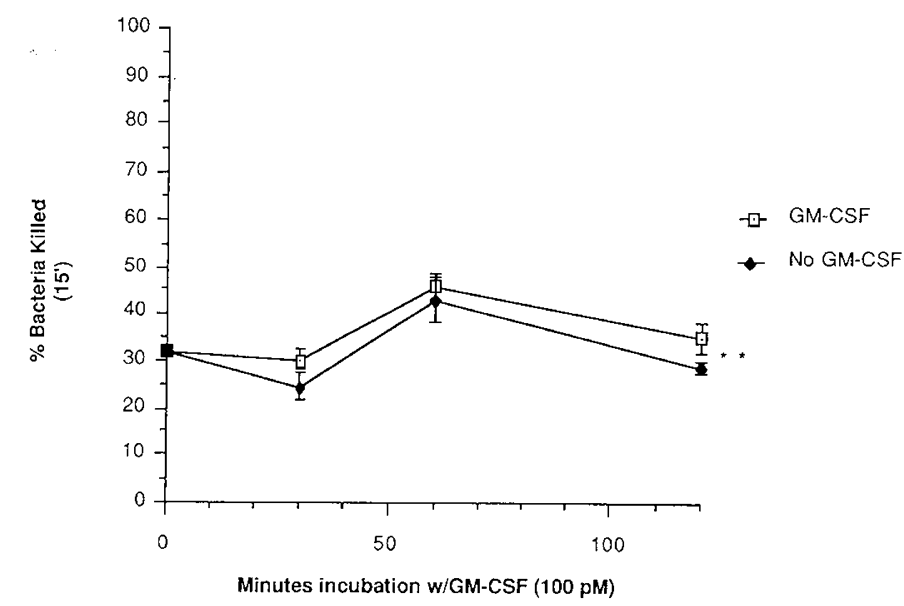

Fig. 4. Bacterial killing capability was measured by a modification of the Quie method as described. Staphlococcus aureus was subcultured and opsonized with cord or control serum. PMN were incubated at various times with $100 \mathrm{pM} \mathrm{GM}-\mathrm{CSF}$ at $37^{\circ} \mathrm{C}$. The treated and untreated cells were mixed with the opsonized bacteria and killing was allowed to progress for $15 \mathrm{~min}$. Colony growth was measured after overnight incubation and results are expressed as mean percent bacteria killed \pm SEM for six experiments.

in a more preactivated state compared to newborn peripheral PMN or adult peripheral PMN. Our adult PMN studies like Weisbart et al. (8), demonstrated that maximal enhancement occurred at a later time interval of incubation, 60-120 min, and was more pronounced compared to neonatal PMN. This difference in maximal enhancement in adults versus neonatal PMN may be secondary to increased amounts of superoxide generation in newborn PMN versus that found in adult PMN $(22,28)$.

Our studies corroborate the adult PMN results of Weisbart et al. $(8,9)$ who reported that GM-CSF primed for increased superoxide generation after 4-5 min after FMLP stimulation. Although our results only represent the effect of GM-CSF priming superoxide generation in cord PMN after 5 min of FMLP stimulation, previous adult PMN data have also shown this priming effect to occur in a continuous assay. The failure of rhGM-CSF to prime neonatal PMN for enhanced effects with PMN stimulation may in part be secondary to a normally increased response of PMA-stimulated PMN superoxide release compared to other agonists (Table 1). Weisbart et al. (9) also failed to document enhancement of rhGM-CSF with PMA stimulation in adult PMN. He noted that the rhGM-CSF enhanced effect might be related to increased expression of surface active chemotactic receptors (FMLP) (9). This hypothesis is consistent with the fact that PMA has a direct effect on protein kinase $C$ activation, by passing the need for upregulation and expression of surface active receptors necessary for signal transduction commonly demonstrated during FMLP and ZAS stimulation.

Neonatal PMN chemotaxis in this study seem to parallel the effects found with rhGM-CSF enhancement with adult PMN (9). Incubation with $100 \mathrm{pmol} / \mathrm{L}$ rhGM-CSF enhanced early (within $5 \mathrm{~min}$ ) chemotaxis with both FMLP and $E$. coli filtrate as chemoattractants in neonatal PMN compared to maximal enhancement at 5-15 min with $100 \mathrm{pmol} / \mathrm{L}$ rhGM-CSF with adult PMN. Weisbart et al. (9) demonstrated a 3-fold increase in the expression of high affinity FMLP surface receptors during a 5to 15 -min exposure of $100 \mathrm{pmol} / \mathrm{L}$ rhGM-CSF with adult PMN. Additionally, Weisbart et al. (9) studied the effects of more prolonged incubations of rhGM-CSF (1-2 h) with adult PMN and concluded that the increase in oxidative metabolism seen at 1-2 h post-rhGM-CSF incubation was secondary to an increase of low affinity FMLP surface receptors.

Bacterial killing was enhanced after a 120-min incubation of neonatal PMN with $100 \mathrm{pmol} / \mathrm{L}$ rhGM-CSF. Fleischmann et al. 
(10) reported enhanced phagocytosis of opsonized $S$. aureus with $100 \mathrm{pmol} / \mathrm{L}$ rhGM-CSF after 15 and $120 \mathrm{~min}$ incubation with adult PMN. However, they did not document any increase in intracellular killing at 30,60 , or $120 \mathrm{~min}$. Baldwin et al. (27), however, administered daily intravenous rhGM-CSF to AIDS patients with defects of PMN bacterial killing and documented a correction of their in vitro abnormality. It is intriguing that our study demonstrated that rhGM-CSF increased neonatal PMN chemotaxis, superoxide production, and intracellular bacterial killing in a temporal fashion resulting in an early effect on PMN locomotion, then a later maximal effect on increased PMN oxygen radical formation eventually resulting in a much later effect on bacterial killing.

The mechanism by which rhGM-CSF primes PMN for enhanced physiologic responses is still under investigation. Naccache et al. (29) recently demonstrated that rhGM-CSF inhibits the cytoplasmic alkalinization which commonly follows stimulation with agonists such as FMLP, PMA, $\mathrm{LTB}_{4}$, and also potentiates the mobilization of intracellular calcium. Sullivan et al. (30) reported that rhGM-CSF primes adult PMN by increasing the rate of membrane depolarization induced by FMLP and enhances release of arachidonic acid from PMN plasma membranes. These latter findings are consistent with Dahinden et al. (31) who recently demonstrated an increase in leukotriene production in human adult PMN primed with rhGM-CSF. Additionally, rhGM-CSF does not directly stimulate protein kinase $\mathrm{C}$ activity (30). Although the mechanism of rhGM-CSF priming PMN is unknown, it is speculative to suggest that following upregulation and expression of surface active receptors (9), rhGM-CSF enhances the increase in a second messenger such as an arachidonic acid metabolite or intracellular calcium. This increase in a second messenger may activate signal transduction pathways in human PMN and subsequently enhance physiologic activity.

This study has demonstrated that GM-CSF moderately enhances neonatal oxidative metabolism, and mildly improves chemotaxis and bacterial killing. RhGM-CSF is currently undergoing in vivo evaluation in adults after intensive chemotherapy regimens, bone marrow transplantation, and additionally to treat patients with AIDS, aplastic anemia, and myelodysplastic syndromes. However, few in vivo trials with GM-CSF have been studied in children. Our preliminary results, however, suggest that rhGM-CSF does enhance in vitro neonatal PMN functional activity and warrants further in vitro neonatal myeloid investigations.

Acknowledgments. The authors thank Nancy Franks for her expert editorial assistance and the OB-GYN Nursery Staff at St. Joseph Hospital for helping to obtain cord blood for this study.

\section{REFERENCES}

1. Wong G, Witek JS, Temple PA, Wilkens KM, Leary AC, Luxenberg DP, Jones SS, Brown EL, Kay RM, Orr EC, Shoemaker C, Golde DW, Kaufman RJ, Hewick RM, Want EA, Clark SC 1985 Human GM-CSF: molecular cloning of the complementary DNA and purification of the natural and recombinant proteins. Science 228:810-815

2. Clark SC and Kamen R 1987 The human hematopoietic colony-stimulating factors. Science 236:1229- 1237

3. Sieff CA 1987 Hematopoietic growth factors. J Clin Invest 79:1549-1557

4. Cannistra SA, Griffin JD 1988 Regulation of the production and function of granulocytes and monocytes. Semin Hemat 25:173-188

5. Sieff CA, Emerson SG, Donahue R, Nathan DG, Wang EA, Wong GG, Clark SC 1985 Human recombinant granulocyte macrophage colony stimulating factor: A multilineage hematopoietin. Science 230:1171

6. Gasson JC, Weisbart RH, Kaufman SE, Clark SC, Hewick RM, Wong GG,
Golde DW 1984 Purified human granulocyte macrophage colony stimulating factor: Direct action on neutrophils. Science 226:1339-1342

7. Weisbart RH, Golde DW, Clark SC, Wong GG, Gasson JC 1985 Human granulocyte-macrophage colony-stimulating factor is a neutrophil activator. Nature 314:361-363

8. Weisbart RH, Kwan L, Golde DW, Gasson JC 1987 Human GM-CSF primes neutrophils for enhanced oxidative metabolism in response to the major physiological chemoattractants. Blood 69:18-21

9. Weisbart RH, Golde DW, Gasson JC 1986 Biosynthetic human GM-CSF modulates the number and affinity of neutrophil f-Met-Leu-Phe receptors. J Immunol 137:3584-3587

10. Fleischmann J, Golde DW, Weisbart RH, Gasson JC 1986 Granulocytemacrophage colony-stimulating factor enhances phagocytosis of bacteria by human neutrophils. Blood 68:708-711

11. Arnaout MA, Wang EA, Clark SC, Sieff CA 1986 Human recombinant granulocyte-macrophage colony-stimulating factor increase cell-to-cell adhesion and surface expression of adhesion-promoting surface glycoproteins on mature granulocytes. J Clin Invest 78:597-601

12. Wilson CB 1986 Immunologic basis for increased susceptibility of the neonate to infection. J Pediatr 108:1-12

13. Hill HR 1987 Biochemical, structural and functional abnormalities of polymorphonuclear leukocytes in the neonate. Pediatr Res 22:375-382.

14. Gasson JC, Kaufman SE, Weishart RH, Tomonaga M, Golde DW 1986 Highaffinity binding of granulocyte-macrophage colony-stimulating factor to normal and leukemic human myeloid cells. Proc Natl Acad Sci USA 83:669774

15. Cairo MS, Mallet C, van deVen C, Kempert P, Bennetts GA, Katz J 1986 Impaired in vitro polymorphonuclear function secondary to the chemotherapeutic effects of Vincristine, Adriamycin, Cyclophosphamide, and actinomycin-D. J Clin Oncol 45:798-804

16. Babior BM, Kipres RS, Curanthe QQ 1973 Biologic defense mechanism: the production of leukocytes of superoxide, a potent bacterial agent. J Clin Invest $52: 741-763$

17. Gallin JJ, Clark RA, Kimball HR 1973 Granulocyte chemotaxis: An improved in vitro assay employing $51 C R$ labelled granulocytes. J Immunol 110:233236

18. Quie PG, White SG, Holmes B, Good RA 1967 In vitro bactericidal capacity of human polymorphonuclear leukocytes diminished activity in chronic granulomatous disease of childhood. J Clin Invest 46:668-676

19. Miller M 1971 Chemotactic function in the human neonate: humoral and cellular aspects. Pediatr Res 5:487-492

20. Krause PJ, Herson VC, Bontin-Lebowitz J, Eisenfeld L, Block C, LoBello T, Maderazo E 1986 Polymorphonuclear leukocyte adherence and chemotaxis in stressed and healthy neonates. Pediatr Res 20:296-300

21. Miller ME 1969 Phagocytosis in the newborn. Humoral and cellular factors. J Pediatr 75:255-259

22. Ambruso DR, Altenburger KM, Johnston RB 1979 Defective oxidative metabolism in newborn neutrophils: discrepancy between superoxide anion and hydroxyl radical generation. Pediatrics 64:722-725

23. Shigeoka AO, Charette RP, Wyman ML, Hill HR 1981 Defective oxidative metabolic responses of neutrophils from stressed neonates. J Pediatr 98:392398

24. Shigeoka A Santos, J, Hill H 1979 Functional analysis of neutrophil granulocytes from healthy infected and stressed newborns. J Pediatr 95:454-460

25. Cairo MS, Worcester C, Rucker R, Bennetts GA, Amlie R, Perkin R, Anas N, Hicks D 1987 Role of circulating complement and polymorphonuclear leukocyte transfusion in treatment and outcome in critically ill neonates with sepsis. J Pediatr 110:935-941

26. Mayer P, Lam C, Obenaus H, Liehl E, Besemer J 1987 Recombinant human GM-CSF induces leukocytosis and activates peripheral blood polymorphonuclear neutrophils in nonhuman primates. Blood 70:206-213

27. Baldwin GC Gasson JC Quan SG, Fleischmann J, Weisbart R, Oette D, Mitsuyasu RT, Golde DW 1988 Granulocyte-macrophage colony-stimulating factor enhances neutrophil function in acquired immunodeficiency syndrome patients. Proc Natl Acad Sci USA 85:2763-2766

28. Yamazaki M, Matsuoka T, Yasu K, Komiyama A, Akabane T 1988 Increased production of superoxide anion by neonatal polymorphonuclear leukocytes stimulated with a chemotactic peptide. Am J Hematology 27:169-173

29. Naccache PH, Faucher N, Borgeat P, Gasson JC, DePersio JF 1988 Granulocyte-macrophage colony-stimulating factor modulates the excitation-response coupling sequence in human neutrophils. J Immuno 140:3541-3546

30. Sullivan R, Griffin JD, Simons ER, Schafer AI, Meshulam T, Fredette JP, Maas AK, Gadenne AS, Leavitt JL, Melnick DA 1987 Effects of recombinant human granulocyte and macrophage colony-stimulating factors on signa transduction pathways in human granulocytes. J Immuno 139:3422-3430

31. Dahinden CA, Zingg J, Maly FE, DeWeck AL 1988 Leukotriene production in human neutrophils primed by recombinant human granulocyte/macrophage colony-stimulating factor and stimulated with the complement component C5A and FMLP as second signals. J Exp Med 167:1281-1295 